\title{
Development of a Yam Harvester using Finite Element Method
}

\author{
C.K. Bosrotsi*, A. Addo, K. A. Dzisi, S. K. Agodzo \\ Department of Agricultural and Biosystems Engineering \\ Kwame Nkrumah University of Science and Technology, \\ Kumasi, Ghana
}

\begin{abstract}
Yam is a tuber crop and its harvesting is a major challenge as a result of drudgery and high manpower requirement. Therefore, the objective of this study was to develop a tractor operated implement for the mechanization of yam harvesting. The most important component of a root and tuber harvester is the blade since it interacts directly with the soil as it cuts through the soil. During such operations, the blade is subjected to impact and high frictional forces that creates unbalanced forces which results in blade wear. In this research, different geometric model concepts of blades were modelled using CAD and McKyes three dimensional model was used to predict the draft force. Finite element method was implemented in ANSYS software and the trapezoidal-shape of blade was found to have a deformation of $0.0535 \mathrm{~mm}$ with a stress of $97.856 \mathrm{MPa}$. The finite element analysis results for the entire harvester assembly generally showed a maximum stress of $218 \mathrm{MPa}$ which was less than the material stress of $250 \mathrm{MPa}$. This suggests that the entire harvester assembly was designed within the safe stress levels.The harvester was fabricated and tested under experimental field conditions.
\end{abstract}

Keywords: Yam harvester, finite element analysis, blade, mechanisation

\section{INTRODUCTION}

Yam is an important food security and cash crop in most countries of the West African sub-region. According to Rees and Bancroft (2003), yams produced in these countries contribute about 95-96\% of the world's total production. Ghana is ranked the second largest producer of yam in the world after Nigeria (FAOSTAT, 2013). Among all the staple root and tuber crops, yam, with an annual production of approximately 6.3 million tonnes is the most cultivated in Ghana (MoFA SRID, 2011). Yams are grown in almost all the agro-ecological zones in Ghana and statistics indicate a gradual increase in yam production over the past few decades (Ennin et al., 2009); which is an indication of the enormous potential of the crop nationwide.

Harvesting has been identified as a crucial, yet labour-intensive operation in the production of yam. It involves standing, bending, squatting, and even sitting on the ground sometimes, depending on the size of mound, tuber size, or the depth of tuber penetration (Opara, 2003). Mohammed and Sealy (2013) reported that physical damage during harvesting operations can be the major cause of postharvest losses in roots and tubers. Unfortunately, the use of existing rudimentary tools for yam harvesting is usually associated with high tuber damage, leading to substantial levels of post-harvest losses. According to Sanginga (2015), post-harvest losses for root and tuber crops can be as high as $40 \%$ of total production.

Over the years, increases in yam production have been achieved mainly due to increase in the area under cultivation, development and release of higher yielding varieties through scientific research and adoption of some improved methods of cultivation (Ennin et al., 2009; Bergh et al., 2012).

The blade is the most important component of a root and tuber harvester. It is subjected to impact and high friction during operation which results to the wearing of the blade. These high stress accompanied with friction are influenced by blade geometry, the rake angle, the soil condition, the blade material, blade support and speed of the blade moving in the soil and these factors reduces the blade's service/ working life. Hence, proper design of the harvester's blade is very important in order to increase its working life time and reduce the harvesting costs (Mollazade et al., 2010).

This research focuses on selecting the most optimal blade based on structural integrity using the finite element analysis (FEA). The FEA method is a powerful numerical technique that can be used to analyze complex engineering problems and it represents one of several methods which are used for 


\section{C.K. Bosrotsi et al.}

evaluating a structure under static and dynamic loads(Upadhyaya el al., 2002). This method also allows full three-dimensional simulation without compromising the geometrical details (Hughes 2000; Madenci and Guven, 2007). Finite element method was used by many researchers to design tillage tools or investigate the interaction between soil and tillage implement (Shinde et al., 2011; Alavi and Hojati, 2012). Therefore, the objective of this study was to use FEA to develop a yam harvester for fabrication.

\section{Materials AND Methods}

\subsection{Size and Geometric Properties of Yam}

Data on yam tuber length, its roundness and orientation in the mound are important in the design of depth of penetration of root and tuber harvester blade. Field study was carried out at Adaklu Mangotideke-Ho and Nkwantain the Volta Region, and Fumesua and Ejura in the Ashanti region. These locations form part of the major yam growing areas in Ghana. The purpose of the data collection was to design a harvester for universal usage in the country. The study involved digging around the mound to expose the yam tuber for size measurements. Such data are important for the design of the depth of penetration of the blade for lifting of the tuber.

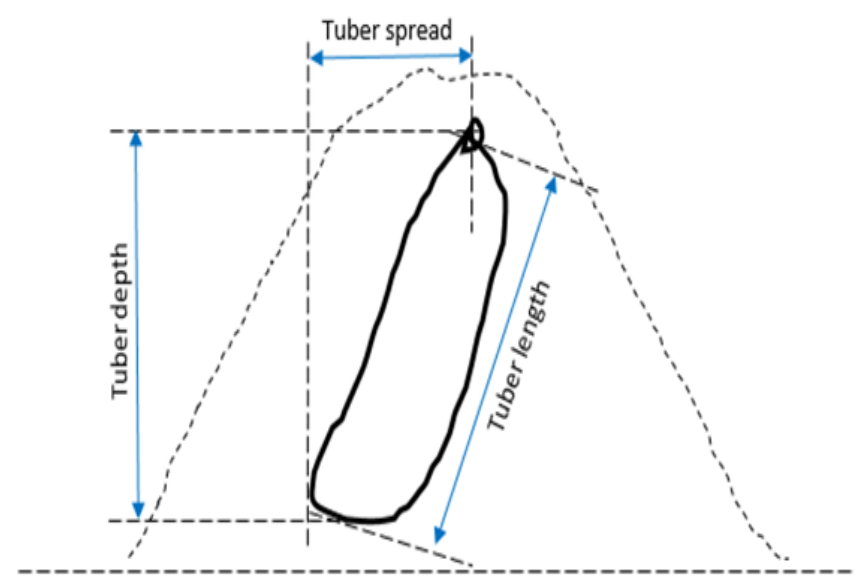

Figure1. Yam tuber depth, spread and length measurements (Bosrotsi et al., 2017).

Table 1presents the geometric data of different yam varieties.

Table1. Geometric data of different yam varieties

\begin{tabular}{|c|c|c|}
\hline Variety & Depth of Tuber $(\mathrm{cm})$ & Circumference $(\mathrm{cm})$ \\
\hline Puna & $30-42$ & $30-35$ \\
\hline Krachi or Kplendzo & $30-42$ & ditto \\
\hline Nyamenti & $30-46$ & ditto \\
\hline Water Yam & $25-35$ & ditto \\
\hline Yellow Yam (Nkafo) & $10-20$ & ditto \\
\hline
\end{tabular}

\subsection{Farm Layout Configuration}

Optimal farm layout configuration is important for ease of yam harvesting mechanisation. Therefore, the proposed farm layouts are the rectangular grid mound and ridge configurations respectively (Figures2a and $2 \mathrm{~b}$ ). The row and inter-row spacings and the dimensions of mound and ridge base, crest and height are presented in Table 2.

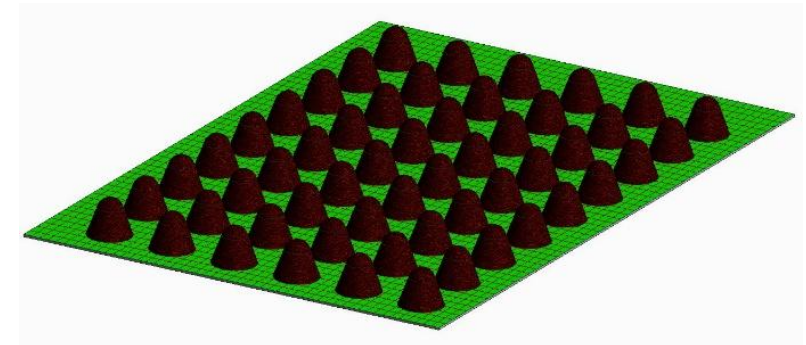

Figure2a.Rectangular grid mound configuration.

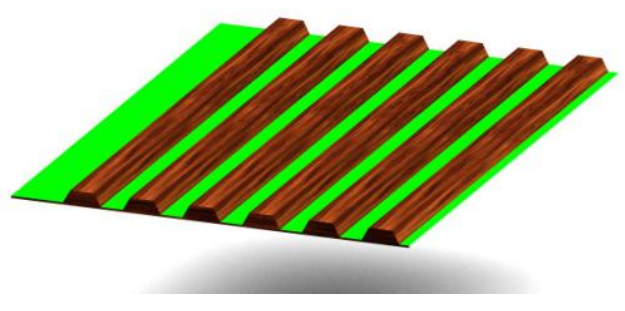

Figure2b: Ridge configuration. 
Finite Element Analysis and the Development of a Yam Harvester

Table2.Yam farm layout data

\begin{tabular}{|l|c|c|}
\hline \multirow{2}{*}{ Land Formation Parameters } & \multicolumn{2}{|c|}{ Farm Layout } \\
\cline { 2 - 3 } & Mound & Ridge \\
\hline Row spacing $(\mathrm{cm})$ & $100-120$ & 120 \\
\hline Inter-row spacing $(\mathrm{cm})$ & $80-100$ & $40-60$ \\
\hline Base $(\mathrm{cm})$ & $50-80$ & 100 \\
\hline Crest width $(\mathrm{cm})$ & $0-5$ & 80 \\
\hline Height $(\mathrm{cm})$ & $80-100$ & $40-60$ \\
\hline
\end{tabular}

\subsection{Computed Aided Design (CAD) Modelling}

Four different conceptual geometries of blades were designed using PTC Creo Parametric 3.0 (a computer aided design modelling software) based on the geometric data and farm layout data from Tables 1 and 2 above. Flat, trapezoidal, triangular and serrated blades were designed with an overall dimensions of $0.3 \mathrm{~m}$ for length and $0.8 \mathrm{~m}$ for breadth. Table 3 shows the conceptual geometric models of the various blades.

Table3. Conceptual geometric models of blade

\begin{tabular}{|c|c|}
\hline Flat blade & Trapezoidal blade \\
\hline Triangular blade & Serrated blade \\
\hline
\end{tabular}

\subsection{Modelling Approach}

Figure 3 shows the flow chart for the modelling of the yam harvester. The data of yam tubers and farm layout configurations were used to develop a geometric (three dimensional) models. These models were designed in PTC Creo Parametric 3.0 CAD software. The geometric models were imported into Static Structural toolbox inside the ANSYS Workbench software where finite element analysis (FEA) was carried out. The simulation results from the various models were compared to show the one with most optimal structural integrity.

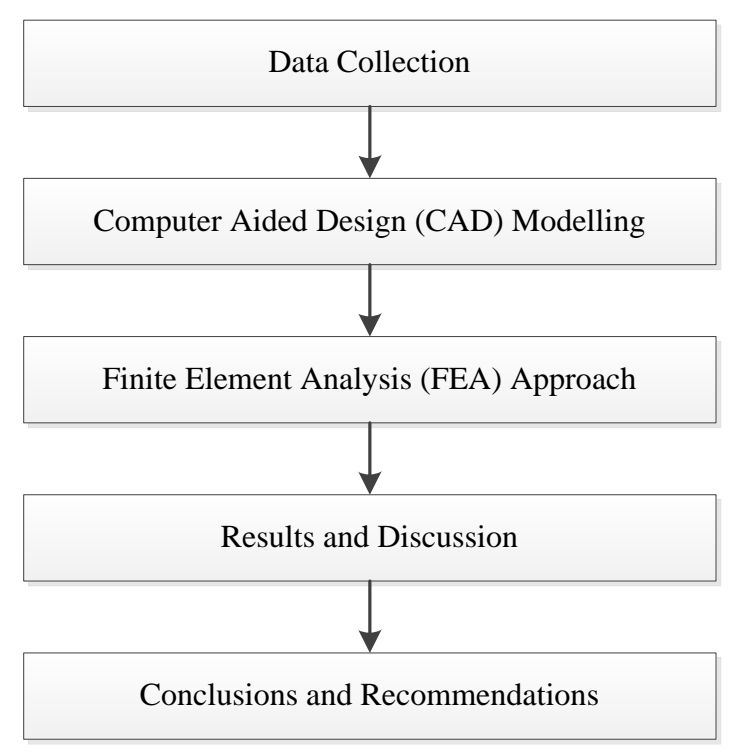

Figure3. Conceptual approach for the study. 


\subsection{Finite Element Analysis (FEA) Approach}

ANSYS Workbench 16.0 which is a commercial FEA software package for carrying out advanced engineering simulations was employed in this research. HP Pavilion dv6 Notebook PC containing an Intel Core i5 processor and six (6) gigabyte random access memory (RAM) was used for the simulation. In the ANSYS Workbench environment, the Static Structural toolbox was selected. This toolbox has a solver called Mechanical APDL which contains series of equations and mathematical models for solving structural related problems. The static structural contains a Design modeler which is an inbuilt CAD system in ANSYS. A CAD model can be created or imported into the Design modeler. After the model has been created or imported in the Design modeler, checks are made on the models, cleaned and repaired if there are inconsistencies.

After the model has been cleaned and repaired, the Model environment is obtained. A mesh is created around the geometric model, this enables equations to be solved at cell/nodal locations. The mesh is refined for high solution gradients and fine geometric details however; the degree of refinement is based on the computing resource available. The finer the mesh the more computing resource and time required. After the mesh quality has been validated, the boundary conditions are assigned to the geometric models. The load is also assigned to models and the simulation is run. After the simulation has completed, the results are post processed to generate the equivalent (Von Mises) stresses and total deformation. The results are compared with the material properties, literature and research objectives. If the results are not satisfactory, the geometric models are updated, the mesh is refined and boundary conditions are reset and simulation is initiated till satisfactory results are obtained. Figure 4 represents the overview of the FEA simulation process.

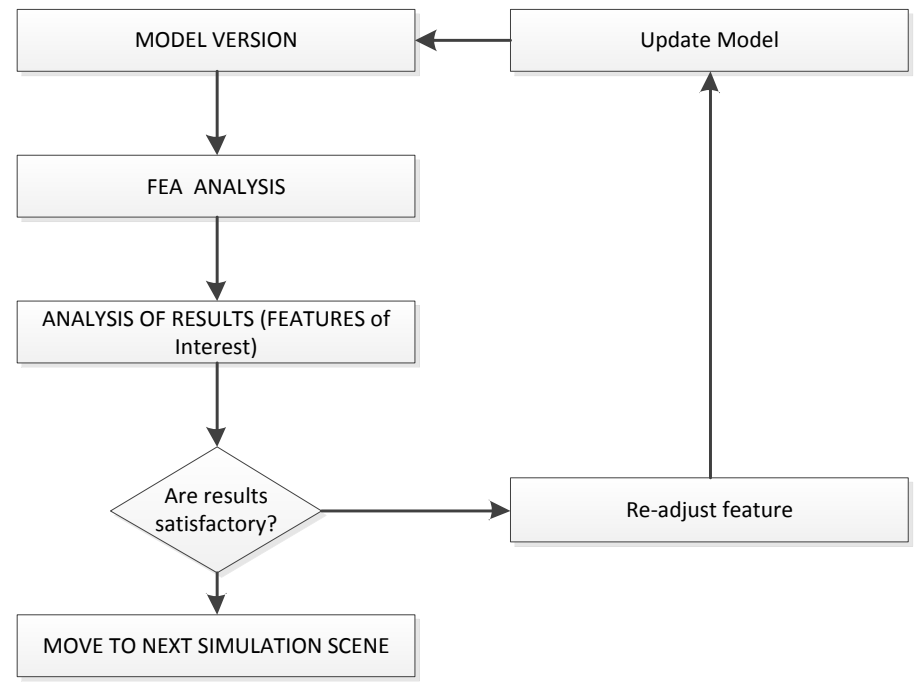

Figure4. Overview of FEA simulation process.

\subsection{Material Properties}

A 36 Structural steel which is most common in Ghana was selected. This material and its properties are presented in Table4. These material properties were specified in the Static Structural Toolbox (ANSYS Workbench 16.0).

Table4. Specification of A 36 structural steel

\begin{tabular}{|c|c|}
\hline Specification & Value \\
\hline Ultimate tensile strength & $450 \mathrm{MPa}$ \\
\hline Yield stress & $250 \mathrm{MPa}$ \\
\hline Bulk modulus & $200 \mathrm{GPa}$ \\
\hline Poisson ratio & 0.26 \\
\hline Elongation at break (in 50mm) & $10 \%$ \\
\hline
\end{tabular}

\section{Model MeShing}

\subsection{Recommended Parameters for the Finite Element Analysis Simulation}

The settings and parameters employed in the simulation of the mechanical yam harvester components are listed in Table 5. 
Finite Element Analysis and the Development of a Yam Harvester

Table5. Static Structural analysis settings in ANSYS Workbench

\begin{tabular}{|l|c|}
\hline \multicolumn{1}{|c|}{ Analysis Parameters } & Settings \\
\hline Material & A36 STEEL \\
\hline Tractor Speed & $1.3 \mathrm{~m} / \mathrm{s}$ \\
\hline Unit System & Metric (mm, kg, N, Degrees, Pa, rad/s, Celsius) \\
\hline Analysis Type & Linear Elastic Static Structural \\
\hline Solver & Mechanical APDL \\
\hline Blade Force & $87,200 \mathrm{~N}$ \\
\hline Environment Temp & $22^{\circ} \mathrm{C}$ \\
\hline Gravity & $9806 \mathrm{~mm} / \mathrm{s}^{2}$ \\
\hline
\end{tabular}

Geometric models were imported from PTC Creo Parametric 3.0 (CAD software) into Static Structural Toolbox (a component of ANSYS Workbench 16.0 software). The geometric models were meshed using the ANSYS Meshing which is a component of the Static Structural tool box in Ansys Workbench 16.0. The mesh enables equations to be solved at cell/nodal locations. Hence, the domain is required to be divided into discrete cells. Due to the simplicity geometrical models of the topologies, ANSYS default mesh size was used. The size of finite models (blades) were approximately 3754 elements and 22132 nodes, 686 elements and 5481 nodes, 2716 elements and 16343, and 3754 elements and 22572 nodes for flat, trapezoidal, triangular and serrated blades respectively. Table 6 shows the geometric and mesh models for the various harvester blade concepts.

Table6.Geometric and mesh models for harvester blade concepts

\begin{tabular}{|c|c|c|c|c|}
\hline \multirow{2}{*}{$\begin{array}{l}\text { Model/ } \\
\text { Contour } \\
\text { Plots }\end{array}$} & \multicolumn{4}{|l|}{ Blade Type } \\
\hline & Flat & Trapezoidal & Triangular & Serrated \\
\hline $\begin{array}{l}\text { Geometri } \\
\text { c Model }\end{array}$ & & & & \\
\hline $\begin{array}{l}\text { Mesh } \\
\text { model }\end{array}$ & ANSYSS & ANSYS & ANSYS & \\
\hline & $\underbrace{4}$ & $\longrightarrow$ - & ב- & 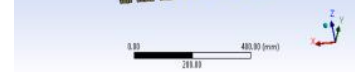 \\
\hline
\end{tabular}

\subsection{Boundary and Loading Conditions}

Fixed support constraints (boundary conditions) were applied into the holes located on the meshed geometric models as there represented the point of attachment to the harvester's shank. Loads (forces) were applied to the cutting edges of the blades to investigate the stresses and deformation and its effect on the blade material. These loads were derived from using the Mckyes and Ali's model for calculating soil forces. Mckyes and Ali's model was adopted in the determination of anticipated soil reaction forces on the blades. This model is a three-dimensional soil failure model without a need for experimental data such as rupture length. The Mckyes and Ali's model assumes flat planes for the bases of wedge centre and circular side crescents in order to define the force direction at the base of failure zone and it also takes into account the speed of the blade moving through the soil. According to experts, the best correlation between analytical and experimental results can be achieved by using Mckyes and Ali's model (McKyes \& Ali, 1977).

Figure 5 shows a wedge shaped zone of blade with width $w$ is assumed in front of the tool, including an undetermined soil failure angle, $\beta$. For each side of the blade is a circular segment with radius $r$ and expending out to a point opposite the lower blade tip. The diameter $r$ and $\mathrm{s}$ are dependent on the angle of the wedge, $\beta$. By determining the appropriate wedge angle, as a function of the amount of soil moved, the effects of the slenderness of the blade and the requirement of moving soil to the slides of the blade can affect the value of the critical wedge angle. The angle, $\beta$, is the function of a function of the blade rake angle and the soil strength. 


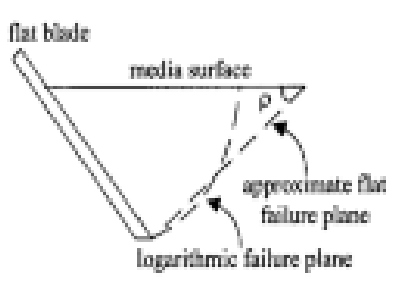

a) Cutting failure planes

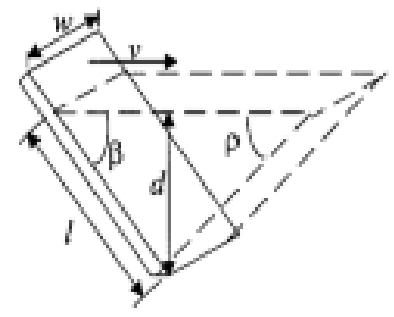

b) Cutting operation variables

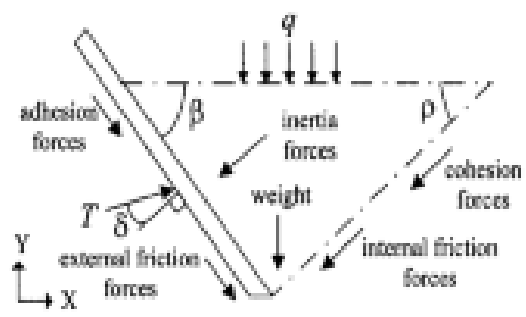

c) Cutting forces

Figure5. Mckyes model - three dimensional soil cutting model (McKyes and Ali, 1977)

Draught force, vertical force, angle of wedge and inertia were determined for the blade using equations 1, 2, 3 and 4 respectively according to McKyes (1985).

Draught force $(D)=\left(w\left(\gamma g d^{2} N_{\gamma}+c d N_{c}+c_{a} d N_{c a}+q d N_{q}+\gamma v^{2} d N_{a}\right)\right)(\sin (\alpha+\delta))$

Vertical force $(V)=\left(w\left(\gamma g d^{2} N_{\gamma}+c d N_{c}+c_{a} d N_{c a}+q d N_{q}+\gamma v^{2} d N_{a}\right)\right)(\cos (\alpha+\delta))$

Angle of wedge $(\beta)=\arctan \left(\frac{1}{10.255(130-2 \varnothing)^{(-0.4316)}}\right)-\left(\frac{1}{\tan (130-2 \varnothing)\left(\frac{180}{3.4159}\right)}\right)$

Inertial $\left(N_{a}\right)=\frac{\tan \beta+\cot (\alpha \beta+\emptyset)}{[\cos (\alpha+\delta)+\sin (\alpha+\delta) \cot (\beta+\varnothing)][1+\tan \beta \cot \alpha]}$

(Mckyes, 1985)

From the equations above, $\gamma$ is the total soil density, $\mathrm{c}$ is soil to tool adhesion strength, $\phi$ is the angle of internal friction of soil, $\alpha$ is the tool angle, $\delta$ is the friction angle between blade and soil, $g$ is acceleration due to gravity, $\mathrm{d}$ is tool working depth below the soil surface, $\mathrm{c}$ is soil cohesion, $\mathrm{w}$ is blade width, and $\mathrm{Na}$ (inertia coefficient) $\gamma, \mathrm{Nc}, \mathrm{Nq}$, and $\mathrm{Nca}$ are factors which are not only dependent on the soil frictional strength, but also on the blade geometry and blade to soil strength properties.

In Ghana, yams are mostly cultivated in sandy loam soils but there is lack of data on engineering properties of locals for this study. Therefore, the study adopted the data by Godwinet al.(2007) for modelling soil draught forces in sandy loam soils. The soil paramters are presented in Table 7and 8for the determination of the draught and vertical forces.

Table7. Soil Parameters used in the analysis (Sandy loam)

\begin{tabular}{|c|c|c|c|c|}
\hline $\begin{array}{c}\phi \\
\text { degree }\end{array}$ & $\begin{array}{c}\gamma \\
\mathrm{kN} / \mathrm{m}^{3}\end{array}$ & $\begin{array}{c}\mathrm{c} \\
\mathrm{kN} / \mathrm{m}^{2}\end{array}$ & $\begin{array}{c}\delta \\
\text { degree }\end{array}$ & $\begin{array}{c}\boldsymbol{C} \boldsymbol{a} \\
\mathrm{kN} / \mathrm{m}^{2}\end{array}$ \\
\hline $\mathbf{3 5}$ & 15 & 10 & 22 & 0 \\
\hline
\end{tabular}

Table8. Value of $\mathrm{N} \gamma$, Ncand Nq factors according to the slope of the harvester's blade and soil properties

\begin{tabular}{|c|c|c|}
\hline $\boldsymbol{N} \gamma$ & $\mathbf{N c}$ & $\mathbf{N q}$ \\
\hline $\mathbf{1 . 0 5}$ & 1.38 & 0 \\
\hline
\end{tabular}

\subsection{Blade Parameters Used in the Analysis}

Blade parameters were derived using the McKyes and Ali's earthmoving model, soil parameters and literature. Table 9 shows the parameters and their corresponding values obtained using the McKyes model. From the physical property measurements, it was found that the Nyamenti variety had a depth of pentration of $0.46 \mathrm{~m}$. Therefore, it was assumed that yam tuber penetration depth through the soil is $0.5 \mathrm{~m}$. Sandy loam was considered for the analysis and the average speed of tractor for tillage operations was also considered.

Table9. Blade Parameters used in the analysis

\begin{tabular}{|c|c|}
\hline Parameter & Value \\
\hline Depth of blade in soil (m) & 0.5 \\
\hline Width of blade (m) $^{(\mathbf{m})}$ & 0.85 \\
\hline Rake Angle $^{\circ}$ ) & 60 \\
\hline Tractor Speed (m/s) $^{(\mathbf{s})(\mathbf{k N})}$ & 1.3 \\
\hline Draught (Horizontal force) & 87.2 \\
\hline Vertical force (kN) & 12.05 \\
\hline
\end{tabular}




\section{ReSUlts AND DiscuSSiON}

\subsection{Finite Element Analysis on Harvester Components}

Table 10 shows the total deformation and equivalent stress (Von Mises) contour plots of the FEA simulation carried out on the various blade designs.

Table10. FEA results for harvester blade concepts

\begin{tabular}{|c|c|c|}
\hline Blade Type & Equivalent Stress (MPa) & Total Deformation (mm) \\
\hline Flat Blade & 97.5 & 0.055 \\
\hline Occurs on & Bolt holes & Mid-section of the blade \\
\hline Trapezoidal Blade & 97.9 & 0.054 \\
\hline Max occurs on & Bolt holes & Mid-section of the blade \\
\hline Triangular Blade & 121.3 & 0.064 \\
\hline Occurs on & Bolt holes & Mid-section of the blade \\
\hline Serrated Blade & 116.4 & 0.072 \\
\hline Occurs on & Bolt holes & Mid-section of the blade \\
\hline
\end{tabular}

From the simulation results, Von Mises stress on the flat, trapezoidal, triangular and rectangular blades were 97.5 MPa, 97.9 MPa, 121.3 MPa and 116.4 MPa respectively. These stress distributions are below the yield stress $(250 \mathrm{MPa})$ of the blade specified blade material. Higher stress values were located at the inner bolt holes, which suggest that bolts that can withstand stresses above 122 MPashould be used to secure the blade to the harvester's shank in order to withstand anticipated stresses.

The total deformation values for flat, trapezoidal, triangular and rectangular blades were $0.055 \mathrm{~mm}$, $0.054 \mathrm{~mm}, 0.064 \mathrm{~mm}$ and $0.072 \mathrm{~mm}$ respectively. All the deformation values were within the acceptable limit per the design intent and material specifications of the harvester blade. The maximum deformation of the blade at the mid-section could be attributed to the high amount of force the blade has to overcome during its operation.

The blade geometry, material properties, bolt placements and blade thickness plays a significant role which accounted for the stress and deformation differences in the blade concepts. Studies by Goodman (1919) and others have established that blades with higher stress and deformation values have shorter design life (high rate of wear and fatigue). From Table 9, the results showed that the flat and trapezoidal blades offered minimal stress and deformation values than the other blades (Triangular and Serrated Blades). However, the Trapezoidal Blade which has a chamfered tip for easier soil penetration was selected over the Flat Blade.

Table 11 shows the Finite Element Analysis (FEA) of the geometric models, stress contour plots and deformation contour plots for the various harvester blade concepts. Table 10also shows the total deformation and equivalent stress (Von Mises) contour plots of the FEA simulation carried out on the blades. From the simulation results, Von Mises stress on the flat, trapezoidal, triangular and rectangular blades are $97.5 \mathrm{MPa}, 97.9 \mathrm{MPa}, 121.3 \mathrm{MPa}$ and 116.4 respectively. These stress distributions are below the yield stress $(250 \mathrm{MPa})$ of the specified blade material. Higher stress values were located at the inner bolt holes, which suggest that bolts that can withstand stresses above 122 MPa are to be used to secure the blade to the harvester's shank in other to withstand anticipated stresses.

Total deformation results for flat, trapezoidal, triangular and rectangular blades are $0.055 \mathrm{~mm}, 0.054$ $\mathrm{mm}, 0.064 \mathrm{~mm}$ and $0.072 \mathrm{~mm}$ respectively. All deformation values are within the acceptable limit per the design intent and material specifications of the harvester blade. The maximum deformation of the blade at the mid-section is due to the high amount of force the blade is required to be overcome during operation.

The blade geometry, material properties, bolt placements and blade thickness plays a significant role which accounted for the stress and deformation differences in the blade concepts. From literature, it has been established that blades with higher stress and deformation values have shorter design life (rate of wear and fatigue is high) (Kaplan and Wolff, 2002; Nehru and Asokan, 2015).). The results in Table 10show that the flat and trapezoidal blades have minimal stress and deformation values than the other blades (triangular and serrated blades). It was therefore selected over the other blades. 
C.K. Bosrotsi et al.

Table11. Results of deformation and stress contours of different blade configurations

\begin{tabular}{|c|c|c|c|c|c|}
\hline Blade & Total Deformation Contour Plot & Equivalent Stress Contour Plot & \begin{tabular}{|l|} 
Total \\
Deformation, \\
$\delta_{\max }(\mathbf{m m})$
\end{tabular} & $\begin{array}{l}\text { Equivalent } \\
\text { Stress, } \sigma_{\text {vmax }}(\mathbf{M P a})\end{array}$ & $\begin{array}{l}\text { A36 } \\
\text { Structural } \\
\text { Steel Yield } \\
\text { Stress, } \sigma_{\mathrm{y}}(\mathrm{MPa})\end{array}$ \\
\hline Flat & 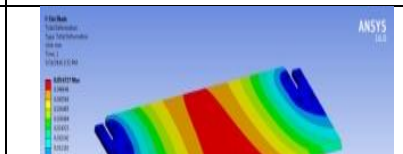 & 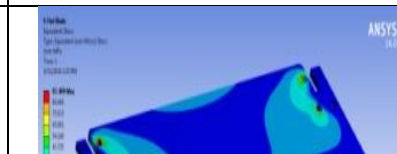 & 0.054727 & 97.499 & 250 \\
\hline Trapezoidal & 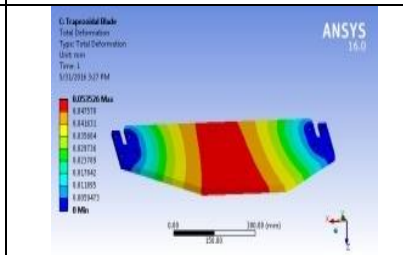 & 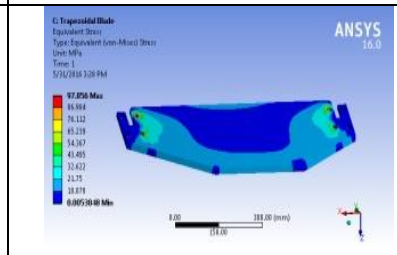 & 0.053526 & 97.856 & 250 \\
\hline Triangular & 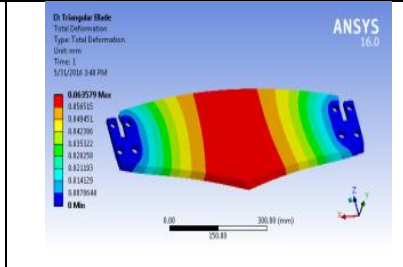 & ANSYS & 0.063579 & 121.26 & 250 \\
\hline Serrated & 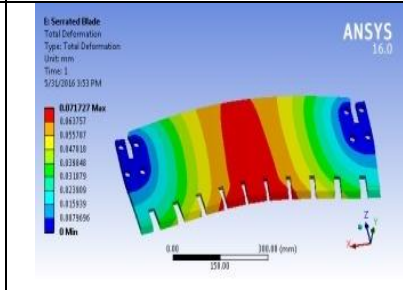 & 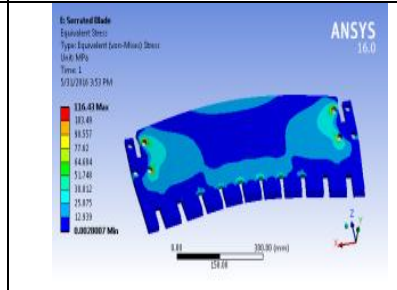 & 0.071727 & 116.43 & 250 \\
\hline
\end{tabular}

Table 12 presents the mesh results for the entire yam mechanical harvester assembly. The results shown that the mechanical yam harvester is expected to weigh a little over $130 \mathrm{~kg}$ after fabrication and can withstand mechanical load of up to $87.2 \mathrm{kN}$ of load.

Table12. FEA mesh results for overall harvester assembly

\begin{tabular}{|c|c|}
\hline Analysis Parameters & Values \\
\hline Mesh Count (Elements) & 126795 \\
\hline Mesh Count (Nodes) & 290822 \\
\hline Harvester Weight & $131.54 \mathrm{~kg}$ \\
\hline Load & $87.2 \mathrm{kN}$ \\
\hline
\end{tabular}

Table 13 presents the Finite Element Analysis results for the entire harvester assembly. The values generally show that $\sigma_{\mathrm{vmax}}<\sigma_{\mathrm{y}}$ (material) (i.e. $218 \mathrm{MPa}<250 \mathrm{MPa}$ ), which suggests that the entire harvester assembly was designed within the safe stress levels.

Table13. FEA results for entire harvester assembly

\begin{tabular}{|c|c|c|c|c|}
\hline $\begin{array}{c}\text { Solution } \\
\text { Objects }\end{array}$ & $\begin{array}{c}\text { Equivalent Stress, } \\
\boldsymbol{\sigma}_{\mathbf{v m a x}}(\mathbf{M P a})\end{array}$ & $\begin{array}{c}\text { Total Deformation, } \\
\boldsymbol{\delta}_{\mathbf{m a x}}(\mathbf{m m})\end{array}$ & $\begin{array}{c}\text { Directional } \\
\text { Deformation } \mathbf{Z} \text { axis }\end{array}$ & $\begin{array}{c}\text { Directional } \\
\text { Deformation Y axis }\end{array}$ \\
\hline Maximum & 218 & 0.054 & 0.0020 & 0.016 \\
\hline Minimum & $1.6605 \times 10^{-10}$ & 0 & -0.0303 & -0.0144 \\
\hline $\begin{array}{l}\text { Maximum } \\
\text { Occurs On }\end{array}$ & Side Supports & Frame & Frame & Frame \\
\hline $\begin{array}{c}\text { Minimum } \\
\text { Occurs On }\end{array}$ & Middle Support & Side Supports & Frame & Frame \\
\hline
\end{tabular}

Figure 6 shows the sequence of FEA static structural analysis and the results generated for harvester. 


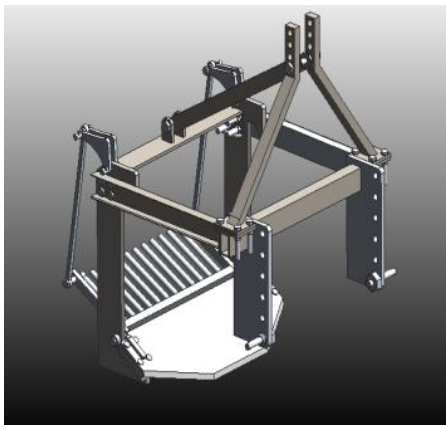

a) 3D model of yam harvester assembly

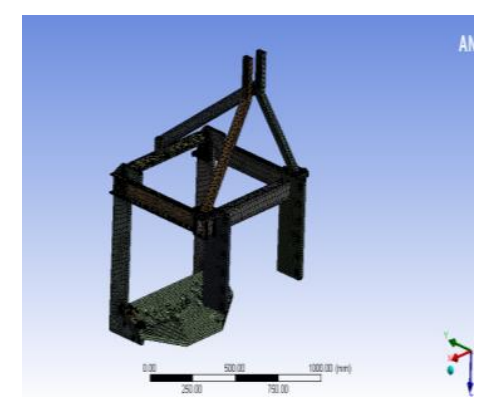

c) Meshed model of yam harvester assembly

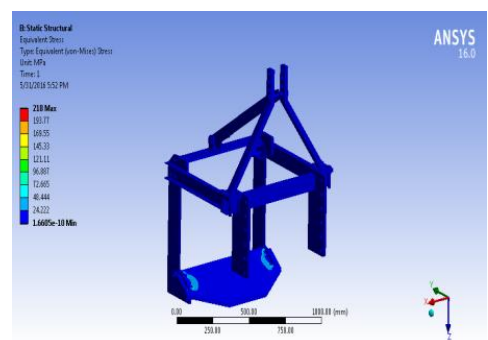

e) Von Mises stress contour plot

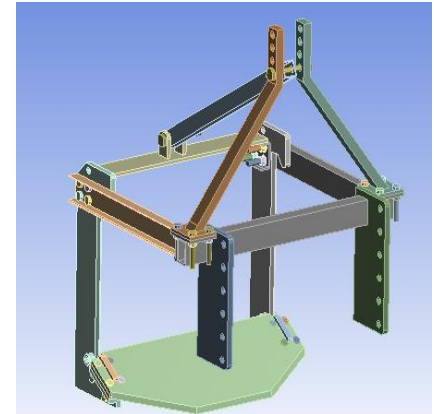

b) Scoped model of yam harvester assembly for FEA simulation

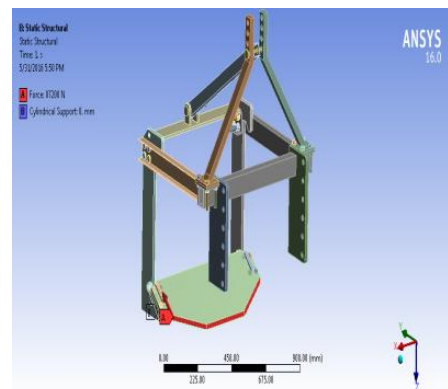

d) Boundary conditions assignment on the harvester

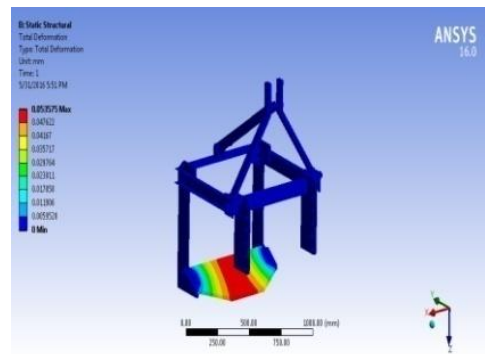

f) Total deformation contour plot

Figure6. Sequence of FEA static structural analysis and results generation for harvester.

Figure 7 shows the fabricated yam harvester, and the performance evaluation is reported by Bosrotsiet al. (2017).
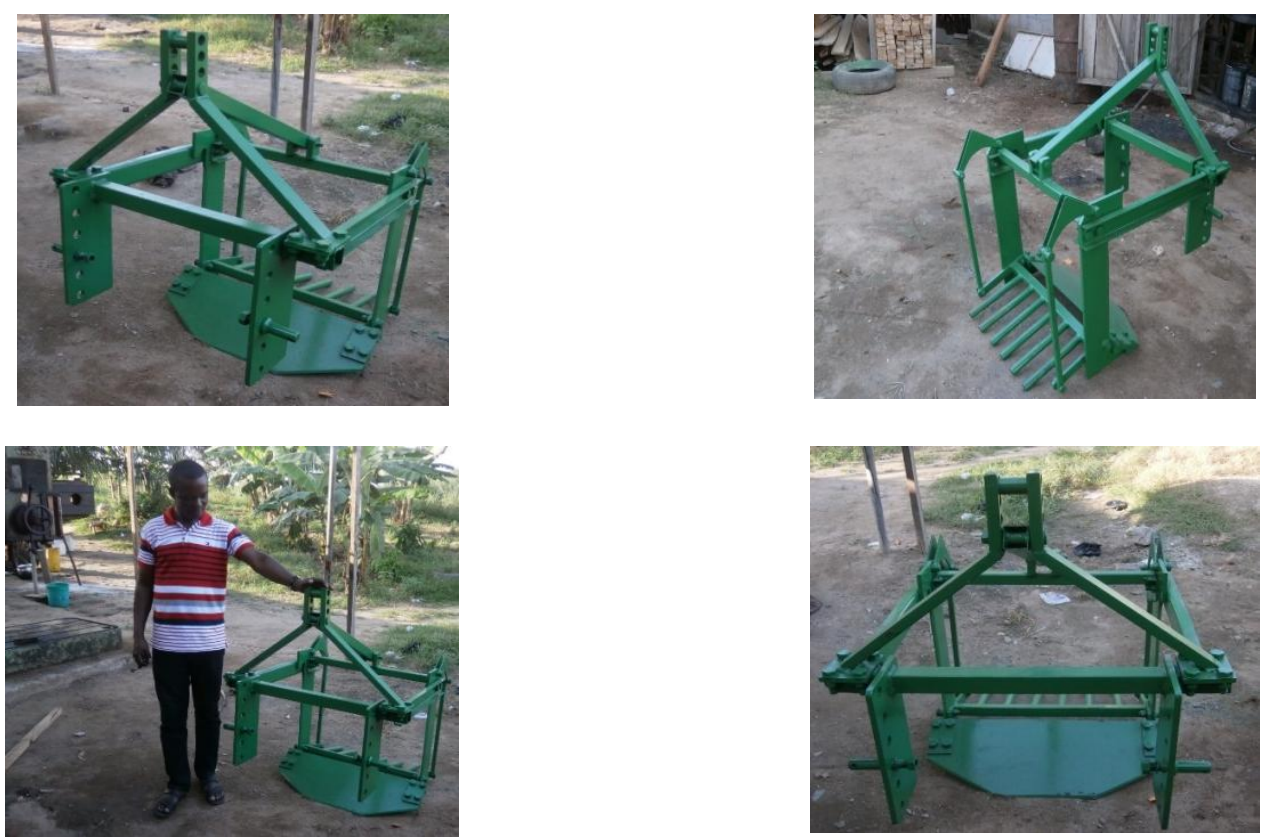

Figure7. The fabricatedmechanical yam harvester. 


\section{Conclusions}

1. The proposed harvester was designed for use by general purpose agricultural tractors with rear track width ranging from $1.10 \mathrm{~m}$ to $1.25 \mathrm{~m}$ with ground clearance range of $0.30 \mathrm{~m}$ to $0.45 \mathrm{~m}$.

2. From the FEA, the trapezoidal blade was selected for its structural integrity and reduced wear rate, and the stresses and deformations acting on values were within the acceptable limits of the material used.

3. The fabrication and assembly of the harvester was successfully carried out at a workshop.

\section{REFERENCES}

[1] Akinbamowo, R. O., Ogunlowo, A. S. and Agbetoye, L. A. S. (2011). Development of a tractormounted cocoyam (Xanthosoma spp.) harvester. Australian Journal of Agricultural Engineering 2(3), 82-89

[2] Alavi, N.and Hojati,R. 2012. Modeling the soil cutting process in rotary tillers using finite element method. Journal of Agricultural Technology 8(1): 27-37.

[3] Anaadumba P. (2013). Analysis of Incentives and Disincentives for Yam in Ghana. Technical Notes Series, MAFAP, FAO, Rome.

[4] Bergh, K., Kpaka, C., Orozco, P., Gugerty, M. K. and Anderson, C. L. (2012). Yam Value Chain: Ghana. EPAR Brief 206. Evans School of Public Affairs, University of Washington, USA.

[5] Diop, A. (1998). Storage and Processing of Roots and Tubers in the Tropics. Food and Agriculture Organization of the United Nations. Rome: Italy.

[6] Ennin, S. A., Otoo, E., \&Tetteh, F. M. (2009). Ridging, a mechanized alternative to mounding for yam and cassava production. West African Journal of Applied Ecology15: 1-8.

[7] Hughes, T.J.R., 2000. The Finite Element Method: Linear Static and Dynamic Finite Element Analysis. $2^{\text {nd }}$ edition. N.Y.: Dover Publicationssher pp. 682

[8] Ihekoronye, A.I. and Ngoddy, P.O. (1985). Integrated Food Science and Technology. New York:Macmilian Publishers. pp. 296-301.

[9] Itodo, I. N. and Daudu, J. O. (2007). Performance evaluation of a yam (dioscorea spp.) harvester. Agricultural Mechanization in Asia, Africa and Latin America 38 (2): 68, 79-83.

[10] Kaplan, M.P. and Wolff, T.A. 2002. Fatigue-Life Assessment, Failure Analysis and Prevention, Vol 11, ASM Handbook, ASM International.

[11] Madenci E, Guven I. 2007.The Finite Element Method and Applications in Engineering Using ANSYS. Springer Publisher,

[12] Mckyes E, Ali O. S., 1977. The cutting of soil by narrow blades. J Terramechanics 14(2): 43-58

[13] Mckyes E. Soil cutting and tillage: development in agricultural engineering 7. Elsevier Press. 1985

[14] Mollzade, K., Jafari and A., Ebrahimi E., 2010. Application of dynamic analysis to choose best subsoiler's shape using ANSYS. Science Journal; 3(3)

[15] Nehru, K and Asokan, R. 2015. Low cycle fatigue analysis of gas turbine blade. National Journal on Advances in Building Sciences and Mechanics. 6(1), 5-9

[16] Opara, L.U. (2003) Yams: Post-Harvest Operation. DaniloMejia (ed.). Rome: FAO

[17] Rees, D. and Bancroft, R. (2003). Development of integrated protocols to safeguard the quality of fresh yams. Crop Post Harvest Programme-Final Technical Report. Natural Resources Institute, University of Greenwich, UK.

[18] Shinde, G. U.,Potekar, J.M., Shinde, R.V., Kajale,S.R. 2011. Design analysis of rotary tillage tool components by CAD-tool: rotavator. Proceedings of the International Conference on Environmental and Agricultural Engineering 15: 1-6.

[19] Sowley, E. N. K., \&Tiesaa, B. (2007). Survey on postharvest problems of yam in Northern Ghana - a case study of the Tolon-Kumbungu District. Ghana Journal of Horticulture, 6, 117121.

[20] Upadhyaya, S. K., Rosa, U. A. and Wulfsohn, D.2002. Application of the finite element method in agricultural soil mechanics. In: Advances in Soil Dynamics 2: 117-153. St. Josseph, Mich.: ASAE. 